\title{
COMPORTAMENTO AGRONÔMICO INICIAL DA CV. CHIMARRITA ENXERTADA EM CINCO PORTA-ENXERTOS DE PESSEGUEIRO ${ }^{1}$
}

\author{
MOACIR DA SILVA ROCHA², VALMOR JOÃO BIANCHI ${ }^{3}$, JOSÉ CARLOS FACHINELLO ${ }^{4}$, \\ JULIANO DUTRA SCHMITZ ${ }^{5}$, MATEUS DA SILVEIRA PASA ${ }^{5}$, JOÃO BAPTISTA DA SILVA ${ }^{6}$
}

RESUMO - O trabalho teve por objetivo avaliar a resposta agronômica da cv. Chimarrita enxertada em cinco porta-enxertos, nas condições edafoclimáticas da região de Pelotas-RS, no período de 2003 a 2005. Durante o período de execução do experimento, foram avaliados o diâmetro do tronco do porta-enxerto e da cultivar-copa, comprimento médio dos ramos principais, volume de copa, massa fresca e massa seca do material vegetal retirado nas podas verde e de inverno, índice de intensidade de poda, massa média dos frutos, produção por planta, eficiência produtiva, produção por hectare, sólidos solúveis totais, firmeza da polpa, diâmetro e coloração dos frutos. O porta-enxerto 'Capdeboscq' induziu o maior crescimento vegetativo na cv. Chimarrita durante os três anos de avaliação, seguido do porta-enxerto 'Okinawa'. Este, por sua vez, induziu o maior rendimento produtivo $\left(1,65 \mathrm{t} \mathrm{ha}^{-1}\right)$. A cv. Capdeboscq proporcionou a obtenção de frutos com maior massa. Os porta-enxertos 'GF 305' e 'Aldrighi' induziram menor desenvolvimento vegetativo e a mais baixa produtividade $(0,52$ t.ha-1) .

Termos para indexação: Prunus persica, produtividade, vigor e eficiência produtiva.

\section{AGRONOMICAL BEHAVIOR OF cv. CHIMARRITA ON FIVE ROOTSTOCKS OF PEACH TREES}

\begin{abstract}
The objective for this study was to evaluate the agronomical behavior of cv. Chimarrita on five rootstocks of peach trees in Pelotas- RS from 2003 to 2005. The variables evaluated were: trunk diameters of the rootstock and of the scion; length of the annual terminal growth; volume of the canopy; fresh and dry weight of the material taken by the summer and winter pruning; pruning intensity index; fruit weight; fruit production per tree; production efficiency; productivity per hectare; total soluble solids; pulp firmness; and fruit diameter and color. It was observed that the trees from: rootstock 'Capdeboscq' promoted higher vegetative growth and larger fruits, followed by the ones from the rootstock 'Okinawa' which promoted the highest yield $\left(1,65\right.$ t.ha $\left.^{-1}\right)$; the rootstock 'GF 305 ' and 'Aldrighi' had the lowest vegetative development and yield $\left(0,52\right.$ t.ha' $\left.{ }^{-1}\right)$.
\end{abstract}

Index terms: Prunus persica; productivity; vigor; production efficiency.

\section{INTRODUÇÃO}

O sucesso do cultivo de pessegueiro na região sul do Estado do Rio Grande do Sul (RS) depende de alguns requisitos importantes, entre os quais está a utilização de mudas com qualidade garantida para obtenção de elevada produtividade do pomar. O porta-enxerto utilizado deve adaptar-se às exigências edafoclimáticas do local de plantio; além disso, a cultivar-copa deve atender à demanda do mercado: frutas de alta qualidade para o consumo in natura ou para a indústria.

Atualmente, existe uma gama de porta-enxertos que podem ser utilizados na cultura do pessegueiro, dentre os quais, as cvs. Aldrighi e Capdeboscq, amplamente utilizados no RS, e outras que ainda estão em fase de teste, como a cvs. GF 305, Tsukuba 1, Okinawa, entre outras.

A cv. Aldrighi foi amplamente utilizada na década de 50 e início dos anos 60 pelos agricultores da região de Pelotas como fruta em conserva, o que facilitava a aquisição de caroços para serem usados na obtenção de porta-enxertos. Essa cultivar apresenta boa afinidade com a maioria das cultivares-copa de pessegueiro utilizada no Sul do Brasil, induzindo vigor médio e apresentando produtividade mediana (Finardi, 1998; Fachinello et al., 2000; Rossi, 2004), enquanto a cv. Capdeboscq produz sementes com elevada capacidade de germinação e um rápido desenvolvimento das mudas no viveiro, características essas que devem ter influenciado na escolha desta como principal porta-enxerto para a região Sul do Brasil (Finardi, 1998).

Dentre os novos porta-enxertos introduzidos no Brasil, a cv. GF 305 caracteriza-se por induzir vigor médio e boa ancoragem, porém tem elevada sensibilidade à asfixia radicular, induz média produtividade e apresenta elevada suscetibilidade a pragas e doenças do solo e a viroses (Barbera \& Monastra, 1995, Loreti \& Massai, 1995). Por outro lado, 'Okinawa' tem porte vigoroso, é resistente aos fitonematóides Meloidogyne incognita, M. javanica e M. mali (Finardi; Cabrera et al., 2000; Fachinello et al., 2000), e sua necessidade de frio para superar a dormência está estimada em 100 horas.

\footnotetext{
(Trabalho 178-06). Recebido em : 09-11-2006. Aceito para publicação em : 17-07-2007.

${ }^{2}$ Eng $^{\circ}$ Agr $^{\circ}$, Dr. Professor do CVG/UFPel. Pelotas-RS-Brasil; e-mail: moasiro@ufpel.tche.br.

$\mathrm{Eng}^{\circ} \mathrm{Agr}^{\circ}$, Dr Professor Adjunto do Departamento de Botânica/IB/UFPel -RS-Brasil

${ }^{4}$ Eng $^{\circ}$ Agr $^{\circ}$, Dr. Professor Titular na Área de Fruticultura da FAEM/UFPel, Pelotas-RS-Brasil; e-mail: jfachi@ufpel.tche.br.

${ }_{5}^{5}$ Aluno de graduação em Agronomia da UFPel, bolsista de iniciação científica do CNPq, Pelotas-RS-Brasil, juliano_dutra_agro@yahoo.com.br e mateus_pasa@yahoo.com.br.

${ }^{6} \mathrm{Eng}^{\mathrm{o}} \mathrm{Agr}^{\mathrm{o}}$, Doutor no instituto de Física e Matemática do IFM/UFPel, Pelotas - RS -Brasil.
}

Rev. Bras. Frutic., Jaboticabal - SP, v. 29, n. 3, p. 583-588, Dezembro 2007 
O porta-enxerto 'Tsukuba 1' caracteriza-se por apresentar folhas de coloração vermelha e é pouco exigente em frio, de tal forma que, nas condições do Rio Grande do Sul, apresenta florescimento e brotação precoces. As cultivares-copa, quando enxertadas sobre esse genótipo, apresentam alto vigor.

Dentre as cultivares-copa de pessegueiro com produção de frutas para o consumo in natura, destaca-se a cv. Chimarrita, a qual se caracteriza por ser uma planta de vigor médio, copa de formato aberto e altamente produtiva, fruto de polpa branca, fundente, firme e semi-aderente, sabor doce, com sólidos solúveis entre 12 a $15^{\circ}$ Brix, película de cor creme-esverdeada, com 40 a $60 \%$ de vermelho. Nas condições de Pelotas, a massa média das frutas pode atingir $120 \mathrm{~g}$, produzindo 50 a $65 \mathrm{~kg} \mathrm{planta}^{-1}$ (Raseira \& Nakasu, 1998).

Buscando otimizar a produção e a qualidade das frutas das cultivares-copa em diferentes condições edafoclimáticas, faz-se necessário testar as mesmas sobre diferentes portaenxertos, a fim de facilitar o manejo e reduzir os custos de produção.

O objetivo deste trabalho foi avaliar o comportamento agronômico da cv. Chimarrita enxertada em cinco cultivares de porta-enxertos de pessegueiro, na região de Pelotas-RS.

\section{MATERIAL E MÉTODOS}

O presente trabalho foi realizado no Centro Agropecuário da Palma, localizado no município de Capão do Leão-RS, com início em meados de julho de 2003 até dezembro de 2005 .

Os porta-enxertos utilizados neste experimento foram das cvs. Aldrighi, Okinawa e Tsukuba 1, provenientes de sementes obtidas de plantas do Banco Ativo de Germoplasma de Prunus (BAG), da UFPel, localizado no Centro Agropecuário da Palma; a cv. Capdeboscq, proveniente de pomar da região de Pelotas e a cv. GF 305, proveniente da Itália. A cv. Chimarrita foi utilizada como copa, proveniente da Embrapa Clima Temperado, Pelotas-RS, sendo a formação das mudas através do processo de enxertia por borbulhia de gema ativa, em dezembro de 2002.

As mudas foram produzidas em sacos de plástico de dois litros, contendo mistura de substrato comercial Plantmax ${ }^{\circledR}$ e solo (na proporção de 1:1, v:v), no viveiro do Departamento de Fitotecnia da Faculdade de Agronomia 'Eliseu Maciel', da Universidade Federal de Pelotas. Quando os porta-enxertos atingiram diâmetro mínimo de $7 \mathrm{~mm}$, medido a $20 \mathrm{~cm}$ do nível do solo, procedeu-se a enxertia.

Em fevereiro de 2003, foram retiradas amostras de solo da área da instalação do pomar para serem submetidas à análise em laboratório e interpretado conforme as recomendações de adubação e calagem para os Estados do Rio Grande do Sul e Santa Catarina (Comissão de Fertilidade do Solo, 1994). Em meados de maio, realizou-se a correção do solo com a aplicação de calcário em toda a área do experimento. A seguir, foi semeada aveia-preta $\left(80 \mathrm{~kg} \mathrm{ha}^{-1}\right)$, de acordo com as recomendações feitas por Gomes (2003), formando uma cobertura vegetal, objetivando a proteção do solo, a redução da erosão e o surgimento de ervas daninhas. Em meados de junho, foram adicionados fósforo e potássio em toda a área do experimento, complementando com três toneladas de esterco curtido de curral, distribuído somente nas linhas de plantio. Após este procedimento, foram preparados os terraços de base estreita, obedecendo à declividade do terreno em forma de curva de nível, distanciadas cinco metros entre linhas, formando-se terraços de base estreita com aproximadamente $1,20 \mathrm{~m}$ de largura por $0,40 \mathrm{~m}$ de altura.

Em julho de 2003, foram plantadas as mudas em espaçamento de 5,0 x 1,5m, totalizando 1.333 plantas ha-1, em covas de aproximadamente $0,30 \mathrm{~m}$ de profundidade.

As plantas foram conduzidas em forma de ' $\mathrm{Y}$ ', obedecendo à altura da inserção das pernadas $(30 \mathrm{~cm}$ do nível do solo), conforme recomendado por Fachinello (2002), Lannini et al. (2002) e Loreti \& Massai (2002).

As variáveis avaliadas, relacionadas à atividade vegetativa, foram:

O incremento anual no diâmetro do tronco dos portaenxertos e enxertos $(\mathrm{mm})$, medido a quatro centímetros acima e abaixo do ponto de enxertia, com auxílio de paquímetro digital, e as medições realizadas em duas posições transversais (na Tabela 1, os dados de diâmetro de tronco relativos ao ano de 2003 representam os valores reais de diâmetro, enquanto os dados dos anos de 2004 e 2005, representam o incremento anual do diâmetro do tronco, a partir dos dados registrados no ano de 2003); incremento no comprimento dos ramos principais, ou seja, dos ramos formadores das pernadas (valores registrados no ano de 2003 referem-se ao comprimento real, enquanto nos anos de 2004 e 2005 são apresentados somente o incremento anual em comprimento); massa média da matéria fresca e seca do material das podas verde e seca (g); índice de intensidade de poda, obtido através da relação entre massa da poda verde e poda de inverno; volume de copa da cv. Chimarrita, expresso em $\mathrm{m}^{3}$, obtido através da fórmula: $\left.[(\mathrm{L} / 2) \times(\mathrm{E} / 2) \times \pi) \times(\mathrm{A})\right] / 3$, onde $\pi=3,1416 ; \mathrm{L}=$ distância superior entre as pernadas; $\mathrm{E}=$ espessura média das duas pernadas, e $\mathrm{A}=$ altura da copa (Figura 1), conforme recomendo por Rossi (2004).

As variáveis avaliadas, relacionadas à produção e eficiência produtiva, foram:

Produção média de frutas por planta $(\mathrm{kg})$; massa média das frutas (em gramas); produção média estimada por hectare; eficiência produtiva obtida pela relação entre a produção por planta e o volume de copa ( $\mathrm{kg}$ de fruta $\mathrm{m}^{-3} \mathrm{de}$ copa).

As variáveis avaliadas, relacionadas às características físico-químicas das frutas, foram:

Teor de sólidos solúveis totais (SST), com o emprego do refratômetro manual de marca Atago; firmeza da polpa, com o emprego de penetrômetro de mão da marca Fruit Pressure Tester modelo FT327, com a ponteira de $8 \mathrm{~mm}$, medida na região equatorial de cada fruta. Em cada repetição, foram escolhidas 10 frutas ao acaso para serem avaliadas, totalizando 40 frutas em cada tratamento.

A coloração dos pêssegos foi medida com colorímetro eletrônico (Minolta 300), usando iluminante D65, com abertura de $8 \mathrm{~mm}$ de diâmetro, calibrado segundo orientação do fabricante. Este aparelho efetua a leitura da cor em escala tridimensional $\mathrm{L}^{*}$ $a^{*} b^{*}$ ou CIELAB, onde os valores de L* correspondem à 
luminosidade ou claridade e variam de 100 (branco) a zero (preto). As coordenadas a* e b* indicam a direção da cor: -a* é a direção do verde $\mathrm{e}+\mathrm{a}^{*}$ a direção do vermelho; - $\mathrm{b}^{*}$ é a direção do azul e $+b^{*}$ a direção do amarelo. A partir destes valores, calcularam-se os valores da tonalidade da cor (ângulo $\mathrm{h}^{\circ}$ ), expressos em graus pela fórmula $\mathrm{h}^{\mathrm{o}}=\tan ^{-1} \mathrm{~b}^{*} / \mathrm{a}^{*}$. O ângulo ${ }^{\circ} \mathrm{h}$ é definido como iniciando no eixo $+\mathrm{a}^{*}$ e é expresso em graus, sendo que $0^{\circ}$ corresponde $\mathrm{a}+\mathrm{a}^{*}$ (vermelha), $90^{\circ}$ corresponde $\mathrm{a}+\mathrm{b}^{*}$ (amarela), $180^{\circ}$ corresponde $\mathrm{a}-\mathrm{a}^{*}$ (verde) e $270^{\circ}$ corresponde $\mathrm{a}-\mathrm{b}^{*}$ (azul). $\mathrm{O}$ ângulo ${ }^{\circ} \mathrm{h}$ é a variável que melhor representa a evolução da cor da epiderme de frutas de pêssegos, a qual se desloca de verde, passa pela amarela e vai em direção à vermelha, durante o processo de amadurecimento, conforme recomendado por Trevisan (2003). Foram realizadas quatro leituras na região equatorial de cada fruta.

Para fazer a observação visual da coloração da epiderme das frutas, obedeceu-se a uma escala de 40 a $60 \%$ e 60 a $80 \%$ da epiderme colorida, de acordo com Raseira \& Nakasu (1998).

$\mathrm{O}$ delineamento do experimento foi em blocos casualizados, com 4 repetições e 64 plantas de bordadura. Os tratamentos avaliados foram compostos dos níveis dos fatores porta-enxerto e ano de avaliação, sendo que, para este último fator, as comparações foram feitas somente entres os dados registrados em 2004 e 2005. A unidade experimental foi formada de cinco plantas em cada repetição.

Os dados foram submetidos à análise da variância, através do teste $\mathrm{F}$, e as médias foram comparadas pelo teste de Duncan $\mathrm{P} \geq 0,05$, com emprego do Software SANEST (Zonta \& Machado, 1995).

\section{RESULTADOS E DISCUSSÕES}

O diâmetro médio do tronco, avaliado no ano de 2003, refere-se aos valores reais registrados no primeiro ano após a enxertada, onde não se verificaram diferenças significativas entre os porta-enxertos, porém para a cv. Chimarrita, enxertada sobre a cv. GF 305, registrou-se o menor valor de diâmetro do tronco, sendo inferiores aos demais tratamentos (Figura 2).

Avaliando o incremento do diâmetro do tronco dos cinco porta-enxertos, verificou-se que, em 2004, a cv. Capdeboscq teve incremento no diâmetro do tronco significativamente superior à cv. Aldrighi e GF 305, porém não diferenciando estatisticamente da cv. Okinawa e Tsukuba 1, sendo que a cv. GF 305 apresentou o menor incremento em diâmetro neste ano (Tabela 1). Não houve diferenças significativas entre os portaenxertos em 2005, mas verificou-se a tendência de as cvs. Capdeboscq, Okinawa e Tsukuba 1 apresentarem maior incremento no diâmetro do tronco em relação às cvs. GF $305 \mathrm{e}$ Aldrighi (Tabela 1).

$\mathrm{Na}$ avaliação do incremento médio do diâmetro do tronco de cada porta-enxerto, da cultivar-copa e do incremento no comprimento dos ramos formadores das pernadas, em relação aos anos de 2004 e 2005, verificou-se que houve diferença significativa para todos os tratamentos. Em 2004, pode-se observar que houve incremento significativamente superior para as três variáveis, em relação a 2005, para todos os porta-enxertos avaliados (Tabela 1). Embora se esperasse maior incremento de diâmetro no ano de 2005, estes resultados são justificados pela ocorrência de uma forte estiagem no referido ano, interferindo no desenvolvimento normal das plantas, uma vez que não se dispõe de sistema de irrigação no pomar.

Para o incremento no diâmetro médio do tronco da cv. Chimarrita, em 2004, não se verificou influência significativa dos porta-enxertos. Em 2005, os porta-enxertos 'Capdeboscq' e 'Okinawa' produziram maior incremento no diâmetro do tronco da cultivar-copa que o 'Aldrighi', mas diferiram das cvs. GF 305 e Tsukuba 1. Com base nos dados da Tabela 1, observa-se que o porta-enxerto 'Capdeboscq' é, de maneira geral, mais vigoroso em relação aos demais e, conseqüentemente, induziu maior vigor na cultivar Chimarrita, confirmando as observações já realizadas por Raseira \& Nakasu (1998). O porta-enxerto 'GF 305' induziu o menor vigor em diâmetro de 'Chimarrita' nas condições edafoclimáticas de Pelotas, resultado este contrário ao descrito por Beckman \& Cummins (1991), que, nas condições edafoclimáticas francesas, este porta-enxerto é considerado vigoroso. Estas diferenças são atribuídas basicamente às condições de solo e clima na região e do efeito da própria cultivarcopa.

Em condições similares ao do presente trabalho, Rossi (2004) verificou que o porta-enxerto 'Aldrighi' foi o mais vigoroso dentre os porta-enxertos testados, porém vale ressaltar que, neste trabalho, não foi testado o porta-enxerto 'Capdeboscq' e a copa era da cv. Granada.

Para a variável comprimento médio dos ramos formadores das pernadas, em 2003, o maior comprimento foi induzido pelos porta-enxertos 'Capdeboscq' e 'Aldrighi', não diferindo significativamente de 'Okinawa', porém foram superiores a 'Tsukuba 1' e 'GF 305', este por sua vez foi o que induziu o menor crescimento, diferindo estatisticamente dos demais porta-enxertos (Figura 2).

O porta-enxerto 'Capdeboscq' mostrou ser o mais vigoroso, induzindo o maior incremento no crescimento dos ramos formadores das pernadas da cv. Chimarrita em 2004, diferenciando-se estatisticamente dos demais porta-enxertos (Tabela 1). Em 2005, 'GF 305' induziu o menor incremento no comprimento dos ramos em relação aos demais porta-enxertos, que não diferiram significativamente entre si. Da mesma forma como observado para a variável diâmetro do tronco, em 2004, todos os porta-enxertos induziram o maior comprimento dos ramos formadores das pernadas, em relação a 2005, devido à forte estiagem desse ano. Segundo Salvador et al. (2002), portaenxertos de pessegueiros, de um modo geral, condicionam o crescimento da cultivar-copa, obedecendo ao vigor e às condições edafoclimáticas do local.

O volume da copa induzida por 'Capdeboscq' foi superior aos demais porta-enxertos durante os dois períodos de avaliação, exceto em 2004, em que não diferiu significativamente de 'Okinawa'. Em 2005, 'GF 305' induziu o menor volume de copa na cultivar Chimarrita, porém não diferindo significativamente de 'Aldrighi' e 'Tsukuba 1' (Tabela 1). Os dados registrados para volume de copa, nos primeiros dois anos de avaliação, vêm confirmar relatos de Raseira \& Nakasu (1998), 
onde citam que a cv. Capdeboscq é considerada um porta-enxerto altamente vigoroso. Com relação à 'Okinawa'e 'Tsukuba 1', embora estas cultivares também sejam consideradas vigorosas, no presente trabalho, verificou-se que estas induziram vigor ligeiramente inferior a 'Capdeboscq'.

Considerando-se as variáveis massa de matéria fresca e seca obtida pela execução da poda da copa, não houve diferença significativa induzida pelos porta-enxertos em 2004, porém verificou-se a tendência de ser maior a massa fresca e seca do material de poda das plantas enxertadas sobre 'Capdeboscq' e 'Okinawa' e menor nas plantas enxertadas sobre 'GF 305'. Essa tendência foi confirmada no ano de 2005, onde se obteve maior massa fresca e seca retirada pela poda das plantas enxertadas sobre a cv. Capdeboscq, em relação aos demais porta-enxertos que não diferiram entre si. Entretanto, manteve-se a tendência da cv. GF 305 induzir menor vigor e, portanto, foi menor a massa fresca e seca de poda das plantas sobre este porta-enxerto (Tabela 2).

Para o índice de intensidade de poda, que representa a relação entre a massa fresca retirada pela poda e o volume de copa, verificou-se que o porta-enxerto 'Capdeboscq' não diferiu dos demais materiais nos dois últimos anos avaliados (Tabela 2), apesar de ter mostrado o material mais vigoroso. Embora o 'GF 305 ' tenha sido inferior aos demais porta-enxertos, não diferiu significativamente de 'Aldrighi'e 'Capdeboscsq'.

No que se refere à produção por planta, produtividade por hectare e eficiência produtiva (expressa $\mathrm{em} \mathrm{kg} \mathrm{cm}^{-1}$ ), o portaenxerto 'Okinawa' foi aquele que induziu a maior produtividade por planta no primeiro ano de produção, enquanto 'GF 305' e 'Aldrighi' mostraram-se menos produtivos, não diferenciando estatisticamente entre si. Os porta-enxertos 'Capdeboscq' e 'Tsukuba 1' obtiveram uma produção intermediária, porém acima da média do experimento e não diferindo entre si (Tabela 3). Embora se tenha registrado diferenças significativas entre tratamentos, para produção e produtividade, essas variáveis deverão ser avaliadas durante os próximos anos para verificar se essas diferenças se confirmam, uma vez que os dados obtidos no primeiro ano de avaliação de um pomar podem não representar corretamente a tendência de produção e produtividade das plantas adultas.

Com relação à eficiência produtiva, baseada no volume da copa, verificou-se que 'Okinawa' e 'Tsukuba 1' também foram superiores aos demais porta-enxertos com 12,9 $\mathrm{kg} \mathrm{m}^{3}$ e 11,41 $\mathrm{kg} \mathrm{m}^{-3}$, respectivamente, não diferindo entre si (Tabela 3 ).

Para a variável sólidos solúveis totais (SST), observou-se que as frutas provenientes de plantas enxertadas sobre 'Capdeboscq' e 'Tsukuba 1' foram superiores a 'GF 305', ambos não se diferenciando estatisticamente de 'Aldrighi' e 'Okinawa' (Tabela 4). Raseira \& Nakasu (1998; 2002; 2003) descrevem que o teor de SST na cultivar Chimarrita varia de 12 a $15^{\circ}$ Brix, o que foi confirmado neste trabalho. Além disso, para Grappadelli \& Sansavini (1998), o teor de SST poderá estar relacionado com a posição das frutas na planta, penetração de luminosidade, sistema de condução e a densidade de plantio do pomar.

Na Tabela 4, pode-se observar que a variável firmeza de polpa de frutas não foi influenciada de forma significativa pelos diferentes porta-enxertos.
A massa média das frutas das plantas enxertadas sobre 'Capdeboscq' foi superior a 'Adrighi' e 'GF 305', porém não diferenciando estatisticamente de 'Okinawa' e 'Tsukuba 1' (Tabela 4). Para todos os porta-enxertos, a massa média das frutas foi inferior àquele característico para a cultivar Chimarrita, normalmente superior a $100 \mathrm{~g}$, conforme citado por Raseira \& Nakasu (1998; 2003). Provavelmente, essa diferença pode estar relacionada ao período de estiagem antes e durante o período de maturação das frutas, pois a precipitação de novembro de 2005 foi apenas de $23,7 \mathrm{~mm}$.

Com relação ao diâmetro médio das frutas, verifica-se que 'GF 305' foi o porta-enxerto em que se obtiveram as menores médias de diâmetro, enquanto não se observaram diferenças significativas entres os demais porta-enxertos (Tabela 3). Esses valores acompanharam a tendência dos valores obtidos para o crescimento vegetativo, diâmetro do tronco de porta-enxerto e da cv. Chimarrita.

Com relação às variáveis coloração da epiderme, luminosidade $\left(\mathrm{L}^{*}\right)$, cor de superfície $\left(\mathrm{a}^{*}\right)$ e tonalidade de cor $\left(\mathrm{h}^{\circ}\right)$ dos pêssegos da cv. Chimarrita, não houve efeito significativo dos porta-enxertos (Tabela 4). Os resultados para a média de cor de fundo $\left(b^{*}\right)$ demonstraram que o porta-enxerto 'Tsukuba 1 ' foi superior ao 'Okinawa', ambos não diferindo de 'Aldrighi', 'Capdeboscq' e 'GF 305'.

Dentre os porta-enxertos mais utilizados no Rio Grande do Sul ('Aldrighi' e 'Capdeboscq'), 'Capdeboscq' foi o que proporcionou a obtenção dos resultados mais positivos para a maioria das variáveis analisadas sobre cv. Chimarrita, nos primeiros anos após a instalação do pomar, enquanto em 'GF $305^{\prime}$ foi aquele de apresentou os piores resultados. Porém, cabe ressaltar que esse melhor desempenho está relacionado ao maior vigor inicial induzido pela cv. Capdeboscq, o qual poderá, ao longo dos anos, resultar na indução de excesso de vigor da cultivar-copa, resultando em menor relação de produção, qualidade de fruto e eficiência produtiva, em comparação aos demais porta-enxertos avaliados. Com isso, faz-se necessário avaliar a resposta agronômica deste pomar por, pelo menos, mais cinco anos, a fim de se ter resultados mais concretos que possam ser utilizados para indicar qual dos porta-enxertos testados pode ser recomendado para a região de Pelotas.

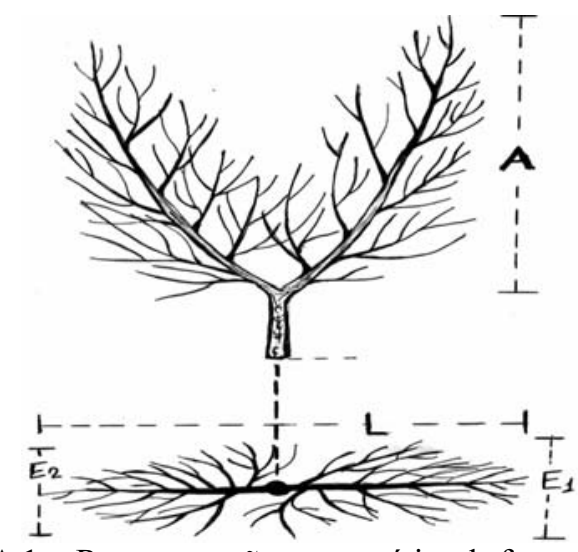

FIGURA 1 - Representação esquemática da forma de condução das plantas e de coleta de dados para cálculo do volume de copa. Pelotas-RS, 2006. 


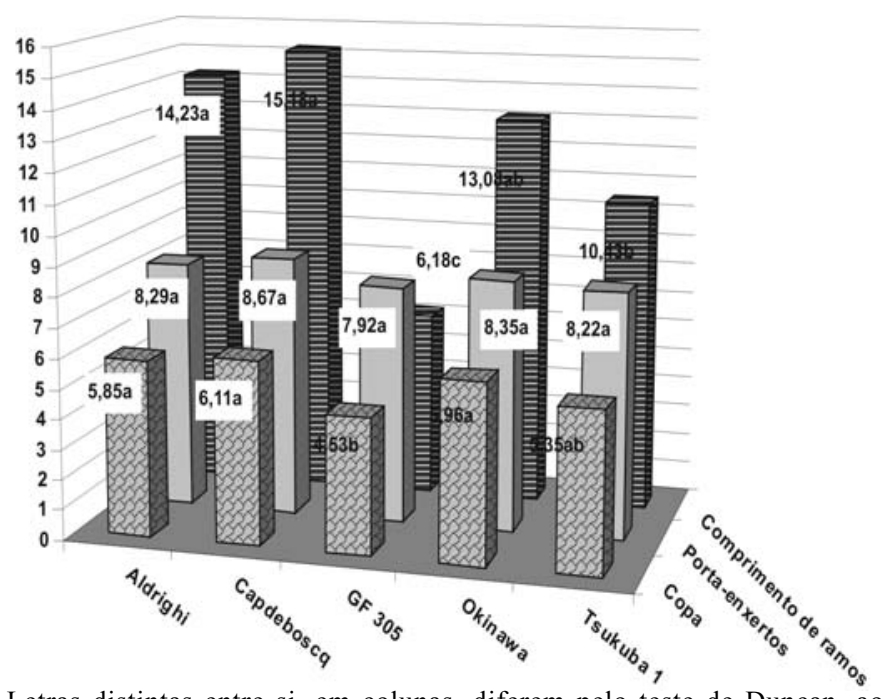

Letras distintas entre si, em colunas, diferem pelo teste de Duncan, ao nível de significância de 0,05 .

FIGURA 2 - Diâmetro médio de diferentes porta-enxertos de pessegueiro e da cv. Chimarrita (em $\mathrm{mm}$ ) e comprimento médio dos ramos formadores das pernadas, avaliada em outubro de 2003. PelotasRS, 2006.

TABELA 1 - Incremento do diâmetro médio do tronco dos portaenxertos e da cv. Chimarrita, incremento no comprimento médio dos ramos formadores das pernadas e volume da copa, avaliado em 2004 e 2005. FAEM/UFPel. Pelotas-RS, 2006.

\begin{tabular}{|c|c|c|c|c|c|c|c|c|}
\hline \multirow[t]{2}{*}{$\begin{array}{l}\text { Porta- } \\
\text { enxertos }\end{array}$} & \multicolumn{2}{|c|}{$\begin{array}{l}\text { Diâmetro do porta- } \\
\text { enxerto (mm) }\end{array}$} & \multicolumn{2}{|c|}{$\begin{array}{l}\text { Diâmetro do tronco de } \\
\text { Chimarrita (mm) }\end{array}$} & \multicolumn{2}{|c|}{$\begin{array}{l}\text { Incremento no } \\
\text { comprimento das } \\
\text { pernadas (cm) }\end{array}$} & \multicolumn{2}{|c|}{ Volume de copa $\left(\mathrm{m}^{3}\right)$} \\
\hline & 2004 & 2005 & 2004 & 2005 & 2004 & 2005 & 2004 & 2005 \\
\hline Aldrighi & $10,81 \mathrm{bcA}$ & $5,12 \mathrm{aB}$ & $11,10 \mathrm{aA}$ & $4,66 \mathrm{bB}$ & $46,90 \mathrm{bA}$ & $18,33 \mathrm{aB}$ & $0,0285 \mathrm{bB}$ & $0,052 \mathrm{bcA}$ \\
\hline Capdeboscq & $13,56 \mathrm{aA}$ & $7,30 \mathrm{aB}$ & $12,36 \mathrm{aA}$ & 6,61 a B & $61,10 \mathrm{aA}$ & $25,18 \mathrm{aB}$ & $0,0483 \mathrm{aB}$ & 0,118 aA \\
\hline GF 305 & $10,23 \mathrm{cA}$ & $5,46 \mathrm{aB}$ & $12,97 \mathrm{aA}$ & $5,51 \mathrm{abB}$ & $51,23 \mathrm{bA}$ & $12,48 \mathrm{bB}$ & $0,0241 \mathrm{bB}$ & $0,047 \mathrm{cA}$ \\
\hline Okinawa & $13,08 \mathrm{abA}$ & 7,61 aB & $12,12 \mathrm{aA}$ & $6,53 \mathrm{a} \mathrm{B}$ & $49,05 \mathrm{bA}$ & $19,33 \mathrm{aB}$ & $0,0366 \mathrm{abB}$ & $0,066 \mathrm{bA}$ \\
\hline Tsukuba 1 & 12,2labcA & $7,58 \mathrm{aB}$ & $11,24 \mathrm{aA}$ & $6,02 \mathrm{abB}$ & $51,85 \mathrm{bA}$ & $20,43 \mathrm{aB}$ & $0,0226 \mathrm{bB}$ & $0,056 \mathrm{bcA}$ \\
\hline CV \% & 12,80 & 24,55 & 18,10 & 19,07 & 9,12 & 16,25 & 22,63 & 22,63 \\
\hline
\end{tabular}
linhas diferem pelo Teste de Duncan, ao nível de significância de 0,05.

TABELA 2- Massa de material vegetal retirado através da poda de inverno e poda verde da copa e índice de intensidade de poda das plantas de pessegueiro cv. Chimarrita, enxertada em diferentes portaenxertos. FAEM/UFPel. Pelotas-RS, 2006.

\begin{tabular}{|c|c|c|c|c|c|c|}
\hline \multirow[b]{2}{*}{ Porta-enxertos } & \multicolumn{2}{|c|}{2004} & \multicolumn{2}{|c|}{2005} & 2004 & 2005 \\
\hline & $\begin{array}{c}\text { Massa } \\
\text { fresca (g) }\end{array}$ & $\begin{array}{c}\text { Massa seca } \\
(\mathrm{g})\end{array}$ & $\begin{array}{c}\text { Massa fresca } \\
(\mathrm{g})\end{array}$ & $\begin{array}{c}\text { Massa seca } \\
(\mathrm{g})\end{array}$ & \multicolumn{2}{|c|}{$\begin{array}{c}\text { Indice de intensidade } \\
\text { de poda }\left(\mathrm{g}^{-3} \mathrm{~m}^{-3}\right)\end{array}$} \\
\hline Aldrighi & $32,59 \mathrm{a}$ & 9,06 a & $98,17 \mathrm{~b}$ & $39,38 \mathrm{~b}$ & $1.701,5 \mathrm{abA}$ & $1.221,0 \mathrm{aA}$ \\
\hline Capdeboscq & 45,94 a & $10,54 \mathrm{a}$ & 194,20 a & 76,45 a & $1.715,3 \mathrm{abA}$ & $1.198,0 \mathrm{aB}$ \\
\hline GF 305 & 20,99 a & $6,77 \mathrm{a}$ & $81,38 \mathrm{~b}$ & $33,44 \mathrm{~b}$ & $1.399,3 \mathrm{bA}$ & $1.141,4 \mathrm{aA}$ \\
\hline Okinawa & $47,85 \mathrm{a}$ & $13,52 \mathrm{a}$ & $129,53 \mathrm{~b}$ & $50,35 \mathrm{~b}$ & $2.278,8 \mathrm{aA}$ & 1.269,9aB \\
\hline Tsukuba 1 & $34,16 \mathrm{a}$ & $11,54 \mathrm{a}$ & 119,78 b & $54,41 \mathrm{~b}$ & $2.440,0 \mathrm{aA}$ & $1.237,4 \mathrm{aB}$ \\
\hline $\mathrm{CV} \%$ & 41,35 & 44,40 & 41,35 & 44,40 & 33,34 & 33,34 \\
\hline
\end{tabular}

Letras minúsculas distintas entre si na mesma coluna e maiúsculas nas diferentes colunas diferem pelo Teste de Duncan, ao nível de significância de 0,05 .
TABELA 3 - Produção de frutas por planta, produtividade por hectare, eficiência produtiva, massa média e diâmetro médio de frutas da cv. Chimarrita, enxertada em diferentes porta-enxertos, avaliada em 2005. FAEM/UFPel. Pelotas-RS, 2006.

\begin{tabular}{|c|c|c|c|c|c|c|}
\hline \multirow{2}{*}{$\begin{array}{l}\text { Porta- } \\
\text { enxerto }\end{array}$} & \multirow{2}{*}{$\begin{array}{c}\text { Produção } \\
\left(\mathrm{Kg}^{-} \text {Planta }{ }^{-1}\right)\end{array}$} & \multirow{2}{*}{$\begin{array}{l}\text { Produtividade } \\
\left(\text { (tha }^{-1}\right)\end{array}$} & \multicolumn{2}{|c|}{ Eficiência produtiva } & \multirow{2}{*}{$\begin{array}{l}\text { Massa média } \\
\text { das frutas (g) }\end{array}$} & \multirow{2}{*}{$\begin{array}{c}\text { Diâmetro } \\
\text { médio das } \\
\text { frutas }(\mathrm{mm})\end{array}$} \\
\hline & & & $\left(\mathrm{Kg} \mathrm{m}^{-3}\right)$ & $\left(\mathrm{Kg} \mathrm{cm}^{-1}\right)$ & & \\
\hline Aldrighi & $0,548 \mathrm{c}$ & $0,731 \mathrm{c}$ & $7,25 \mathrm{~b}$ & $0,2607 \mathrm{c}$ & $81,03 \mathrm{bc}$ & $52,18 \mathrm{a}$ \\
\hline Capdeboscq & $0,975 \mathrm{~b}$ & $1,300 \mathrm{~b}$ & $6,43 \mathrm{~b}$ & $0,3808 \mathrm{~b}$ & $95.23 \mathrm{a}$ & 53,65 a \\
\hline GF 305 & $0,390 \mathrm{c}$ & $0,520 \mathrm{c}$ & $5,77 \mathrm{~b}$ & $0,1870 \mathrm{c}$ & $69,27 \mathrm{c}$ & $45,93 \mathrm{~b}$ \\
\hline Okinawa & $1,238 \mathrm{a}$ & 1,651 a & $12,90 \mathrm{a}$ & $0,5140 \mathrm{a}$ & $84,65 a b$ & $52,53 \mathrm{a}$ \\
\hline Tsukuba 1 & $0,901 \quad b$ & $1,201 \mathrm{~b}$ & 11,41 a & $0,3930 \mathrm{~b}$ & $84,05 \mathrm{ab}$ & $52,31 \mathrm{a}$ \\
\hline C.V\% & 19,39 & 19,07 & 26,37 & 20,20 & 10,30 & 6,64 \\
\hline
\end{tabular}

Letras distintas entre si na mesma coluna diferem pelo Teste de Duncan, ao nível de significância de 0,05 .

TABELA 4 - Sólidos solúveis totais (SST), firmeza de polpa, coloração da epiderme, luminosidade, cor de superfície, cor de fundo e tonalidade da cor das frutas da cv. Chimarrita, enxertada em diferentes porta-enxertos, avaliada em dezembro de 2005. FAEM/UFPel. Pelotas-RS, 2006.

\begin{tabular}{|c|c|c|c|c|c|c|c|}
\hline \multirow[t]{2}{*}{$\begin{array}{l}\text { Porta- } \\
\text { enxerto }\end{array}$} & \multirow[t]{2}{*}{$\begin{array}{c}\text { SST } \\
\left({ }^{0} \text { Brix }\right)\end{array}$} & \multirow{2}{*}{$\begin{array}{c}\text { Firmeza de } \\
\text { Polpa } \\
\text { (lbs) }\end{array}$} & \multirow{2}{*}{$\begin{array}{c}\text { Coloraçãa } \\
\text { da } \\
\text { epiderme }\end{array}$} & $\begin{array}{c}\text { Luminosida } \\
\text { de }\end{array}$ & $\begin{array}{c}\text { Cor de } \\
\text { superfície }\end{array}$ & $\begin{array}{l}\text { Cor de } \\
\text { fundo }\end{array}$ & $\begin{array}{c}\text { Tonalidade } \\
\text { da cor }\end{array}$ \\
\hline & & & & $\left(\mathrm{L}^{*}\right)$ & $\left(a^{*}\right)$ & $\left(b^{*}\right)$ & $\left(\mathrm{h}^{0}\right)$ \\
\hline Aldrighi & $12,03 \mathrm{ab}$ & $14,02 \mathrm{a}$ & $66,66 a$ & 50,55 a & $10,71 \mathrm{a}$ & $26,38 \mathrm{ab}$ & 70,63 a \\
\hline Capdeboscq & $12,49 \mathrm{a}$ & $12,33 \mathrm{a}$ & $68,20 \mathrm{a}$ & $51,72 \mathrm{a}$ & 08,81 a & $26,90 \mathrm{ab}$ & $71,42 \mathrm{a}$ \\
\hline GF 305 & $11,54 \mathrm{~b}$ & $13,15 \mathrm{a}$ & $65,38 \mathrm{a}$ & $51,82 \mathrm{a}$ & $10,82 \mathrm{a}$ & $28,49 \mathrm{ab}$ & 69,03 a \\
\hline Okinawa & $12,38 \mathrm{ab}$ & $11.78 \mathrm{a}$ & $65,00 \mathrm{a}$ & $51,17 \mathrm{a}$ & 09,93 a & $25,55 \mathrm{~b}$ & $68,82 \mathrm{a}$ \\
\hline Tsukuba 1 & $12,77 \mathrm{a}$ & $12,16 \mathrm{a}$ & $65,00 \mathrm{a}$ & 51,15 a & 11,45 a & $30,75 \mathrm{a}$ & $69,82 \mathrm{a}$ \\
\hline C.V\% & 4,38 & 15,12 & 9,32 & 5,08 & 32,67 & 9,72 & 11,65 \\
\hline
\end{tabular}

Letras distintas entre si na mesma coluna diferem pelo Teste de Duncan, ao nível de significância de 0,05 .

\section{CONCLUSÕES}

Nas condições em que o experimento foi conduzido, concluiu-se que:

1 - O porta-enxerto 'Aldrighi' proporcionou, em plantas da cv. Chimarrita, o menor incremento no diâmetro do tronco em 2005.

2 - O porta-enxerto 'Capdeboscq' influenciou no maior incremento de volume de copa na cv. Chimarrita em 2005.

3- O porta-enxerto 'Okinawa' influencia positivamente no rendimento produtivo da cv. Chimarrita.

4- Os porta-enxertos 'Capdeboscq', 'Okinawa' e 'Tsukuba 1' induziram produção de frutos da cv. Chimarrita com maior massa e diâmetro na primeira produção.

5- O porta-enxerto 'GF 305' induz a mais baixa produtividade em relação aos porta-enxertos testados e a menor massa e diâmetro dos frutos e do tronco da cv. Chimarrita. 


\section{REFERÊNCIAS}

BARBERA, G; MONASTRA, F.; Orientamenti per la Scelta Mandorlo, L'Informatore Agrário, Verona, n.32, p.17-18, 1995. Supplemento.

BECKMAN, T.; CUMMINS, J.N. Rootstock for Peaches. HortScience, Alexandria, v.26, n.8, p.974- 975, 1991.

CABRERA, D; CARRAU, F.; RODRIGUEZ, P.; SORIA, J.; DISIGNA, E. Porta-enxertos para Durazmero em la Zona Litoral Norte del Pais. In: REUNION ANUAL Avances de investigación em Frutales de Carozo y Arandanos, 2000, Uruguai. p.4-6. (Série Actividades de Difusión, .237)

COMISSÃO DE FERTILIDADE DO SOLO-RS/SC Recomendações de adubação e calagem para os estados do Rio Grande do Sul e Santa Catarina. Passo Fundo: Sociedade Brasileira de Ciências do solo. Núcleo Regional do sul, 1994. 224p.

FACHINELLO, J. C.; SILVA, C. A. P.; SPERANDIO, C.; RODRIGUES, A. C. R.; STRELOW, E. Z. Resistência de Portaenxertos para Pessegueiro e Ameixeira aos Nematóides causadores de Galhas (Meloidogyne spp.). Ciência Rural, Santa Maria. v.30, n.1, p.69-72, 2000.

FACHINELLO, J. C. Avanços no manejo do solo e de plantas em pomares de pessegueiro. ENFRUTE, 5., 2002, Fraiburgo, SC. Anais... p.59-66.

FINARDI, N. L. Método de propagação e descrição de portaenxertos. In: MEDEIROS, C. A. B.; RASEIRA, M do C. B. Cultura do pessegueiro. Pelotas: EMBRAPA-CPACT, 1998. p.100-129.

GOMES, F. R. C. Qualificação da fruta e do solo em pomares de pessegueiro manejados com aveia-preta. 2003. $84 \mathrm{f}$. Tese (Doutorado em Fruticultura de Clima Temperado) - Faculdade de Agronomia 'Eliseu Maciel', Universidade Federal de Pelotas, Pelotas, 2003

GRAPPADELLI, L.C.; SANSAVINI, S.. Forme di ellevamento, efficienza degli impianti e qualità delle pesche. In: SANSAVINI, S.; ERRANI, A. Frutticoltura ad alta densità - Impianti, forme di allevamento, e tecniche di potatura. Bologna: Ed. Edagricole, 1998. p.191-235.
LANNINI, C.; CIRILLO, C. FORLANI, M. Estimation of nectarine yield efficiency and light interception by the canopy in different training systems. In: JOHNSON, R. S. \& CHRISOSTO, C. H. (Ed.). Acta Horticulturae, Wageningen, n.592, p.357-365, 2002.

LORETI, F.; MASSAI, R. Orientamento per la scelta dei portinnesti dei fruttiferi: Pesco. L'Informatore Agrario, Verona, n.32, p.37-42, 1995 .

LORETI, F.; MASSAI, R. The high density peach planting system; present status and perspectives. Acta Horticulturae, Wageningen, v.1, n.592, p.377-399, 2002.

RASEIRA, M. do C. B.; NAKASU, B. H. Cultivares: descrição e recomendações. In: MEDEIROS, C. A. B.; RASEIRA, M. do C. B. (Ed.). A cultura do pessegueiro. Pelotas: EMBRAPA-CPACT. 1998. p.29-99.

RASEIRA, M.do C. B; NAKASU, B.H. Pessegueiro. In: BRUCKNER, C.H (Ed.). Melhoramento de fruteiras de clima temperado. Viçosa: Editora UFV, 2002. p.89-126.

RASEIRA, M do C. B.; NAKASU, B. H. Cultivares. In: RASEIRA, M. do C.B.; CENTELlAS-QUEZADA, A. (Ed). Pêssego produção. Brasília: Embrapa Informação Tecnológica, 2003. p.4159.

ROSSI, A. de.; FACHINELLO, J. C.; RUFATO, L., PARISOTTO, E.; PICOLOTTO, L.; KRUGER, L. R. Comportamento do pessegueiro 'Granada' sobre diferentes porta-enxertos. Revista Brasileira de Fruticultura. Jaboticabal, v.26, n.3, p.446-449, 2004.

SALVADOR, F. R. de; ONDRADU, G.; SCALAS, B. Horticultural behaviour of different species and hybrids as rootstocks for peach. Acta Horticulturae, Wageningen, v.1, n.592, p.317-322, 2002.

TREVISAN, R. Avaliação da qualidade de pêssego cultivar Maciel, em função do manejo fitotécnico. 2003. 114 f. Tese (Doutorado em Fruticultura de Clima Temperado) - Faculdade de Agronomia 'Eliseu Maciel', Universidade Federal de Pelotas, Pelotas, 2003.

ZONTA, E.P.; MACHADO, A. A. Sanest-Sistema de análise estatística para microcomputadores. Pelotas: UFPel, 1995. 48 p. (SEI n. 066060, Categoria A) 